\title{
Reflexões psicanalíticas a respeito do vínculo materno na constituição do sujeito
}

\author{
Psychoanalytic reflections about the maternal bond \\ in the constitution of the subject
}

\author{
Ana Alice Fugimoto Saruwatari', Vera Lucia Gaviglia', ${ }^{2}$ Camila de Araujo Antonio ${ }^{3}$ \\ 'Autora para correspondência. UniFil - Centro Universitário Filadélfia. Londrina, Paraná, Brasil. ORCID: 0000-0003-0378-5424. analicesi@hotmail.com \\ ${ }^{2}$ UniFil - Centro Universitário Filadélfia. Londrina, Paraná, Brasil. ORCID: 0000-0002-6064-1526. gavigliavera@hotmail.com \\ ${ }^{3}$ UniFil - Centro Universitário Filadélfia. Londrina, Paraná, Brasil. ORCID: 0000-0003-2595-3361. camila_araujo2@hotmail.com
}

RESUMO | O presente trabalho possui por objetivo refletir acerca dos elementos que se apresentam no desenvolvimento do sujeito, caracterizando as relações parentais e sua implicação na formação do sujeito. Trata-se de um estudo de revisão de literatura com recortes teóricos psicanalíticos realizados por meio de livros e de textos clássicos da psicanálise, objetivando responder como as relações parentais, em especial o vínculo materno, contribuem para a constituição do sujeito e analisar a relevância de tal vínculo para diagnóstico e a prática clínica psicanalítica. $\bigcirc$ método empregado neste trabalho foi a pesquisa bibliográfica tendo como vertente a teoria psicanalítica, a qual norteou o trabalho. Os principais autores usados foram Sigmund Freud, Donald Winnicott e Julieta Jerunsalinsky. Este estudo se tornou relevante, pois discorre sobre a dinâmica envolvida na constituição do sujeito relacionando - desenvolvimento com as funções parentais. Na prática clínica é possível realizar a escuta dos significantes que constituem o sujeito ao longo do desenvolvimento e como consequência proporcionar a ressignificação dos conflitos decorrentes.

PALAVRAS-CHAVE: Psicanálise. Desenvolvimento. Sujeito.

\begin{abstract}
The present work aims to reflect on the elements that present themselves in the development of the subject, characterizing the parental relationships and their implication in the formation of the subject. This is a literature review study with psychoanalytical theoretical sections made through books and classical texts of psychoanalysis, aiming to answer how the parental relationships, especially the maternal bond, contribute to the constitution of the subject and analyze the relevance of such a link to psychoanalytic clinical practice. The method used in this work was the bibliographical research with as its subject the psychoanalytic theory, to which it guided the work. The main authors used were Sigmund Freud, Donald Winnicott and Juliet Jerunsalinsky. This study became relevant because it discusses the dynamics involved in the constitution of the subject relating development to parental functions. In clinical practice, it is possible to listen to the signifiers that constitute the subject throughout development and, as a consequence, to provide a re-signification of the resulting conflicts.
\end{abstract}

KEYWORDS: Psychoanalysis. Development. Subject. 


\section{Introdução}

Freud, o expoente da psicanálise, descreve a importância das relações parentais no processo evolutivo do ser humano e postula que todas as relações sociais da história do indivíduo implicam no seu desenvolvimento. Em especial, este trabalho considera a função materna como diretamente relacionada à constituição psíquica. Há condições para que o bebê possa constituir-se como sujeito e isso se dá por esse laço precoce com seu cuidador.

Parte-se do pressuposto de que a função materna, assim como, a forma como ocorrem a passagem pelas fases do desenvolvimento psicossexual (oral, anal, fálica/genital), sustentadas a partir da teoria das pulsões constituem a formação do aparelho psíquico.

Na sequência será abordada a importância e implicações da função materna utilizando-se de dois autores principais: Donald Wood Winnicott e Julieta Jerusalinsky.

Dois psicanalistas importantes sendo um mais clássico e o outro mais contemporâneo, contudo pode-se perceber uma afluência dos autores no que tange a constituição do sujeito e destacando a importância da função materna que ambos evidenciam em seus relatos, pressupostos diferentes, mas que possuem a mesma finalidade.

Donald W. Winnicott dissertará sobre o processo de subjetivação do sujeito, que ocorre desde o primeiro vínculo, na díade mãe e bebê, onde a função da mãe é primordial para um desenvolvimento saudável, e de igual forma Jerusalinsky, pontuará sobre a fantasmática parental que a depender de toda história dos pais, prepara, desde antes do nascimento, um lugar para que essa criança venha ocupar, e disso dependerá seu processo de amadurecimento e a fundação do desejo no sujeito.

Os autores que foram utilizados para esse trabalho, convergem suas ideias destacando a importância da função materna na constituição do sujeito, mesmo com formas diferentes na abordagem, o sentido se torna o mesmo no final. $O$ que se diferencia é que Winnicott enfatiza mais o aspecto da díade mãe-bebê, e todo esse suporte oferecido pela mãe durante os anos iniciais da criança, enquanto que Jeruzalinsky pontua a pré-história da criança, denotando que tudo começa no desejo e/ou sonho dos pais em constituir uma família, levando em consideração sua própria história pregressa.

E, por conseguinte completando a proposta dessa pesquisa, será discutida a relação terapêutica na clínica em todas as fases da vida, já que a constituição do sujeito não acaba nunca, pois ele sempre se encontra em transformação porquanto, depende da interação com o outro e seus impactos na economia psíquica sempre estará presente.

Dessa forma, o presente trabalho trata-se de uma revisão narrativa de base psicanalítica, que teve como método uma pesquisa exploratória a fim de evidenciar pontos importantes de dois autores descrevendo sobre a dinâmica que ocorre no processo de constituição do sujeito, e, sobretudo evidenciando a importância das relações parentais no processo, em especial a função materna.

\section{Alguns conceitos importantes para a compreen- são desse trabalho}

Sigmund Freud, o pai da psicanálise, foi médico especialista em neurologia, e no fim do século XIX e início do século $X X$ desenvolveu sua teoria relacionando-a com sua prática médica psicoterapêutica. Ele tratava pacientes com problemas nos nervos, e decepcionado com a técnica usualmente empregada na época, à eletroterapia, buscou outras formas de tratamento, e influenciado diretamente por seu colega, o médico Joseph Brever, passou a utilizar a hipnose, até chegar a sua teoria e técnica que ficou conhecida como psicanálise e se realiza por meio da associação livre de ideias.

A teoria psicanalítica de Freud demonstra a etiologia dos transtornos mentais, as fases do desenvolvimento infantil, o processo da constituição do sujeito, além de esclarecer a respeito da formação dos transtornos mentais (PINTO et al, 2007).

Freud (1900) no texto A interpretação de sonhos, procura definir o aparelho psíquico comparando com aparelhos ópticos, fazendo referência á um dos seus Projetos intitulado doutrina anatômica do neurônio, cuja, aceitação pelos neuroanatomis- 
tas era notória no fim da década de 1880. James Strachey na tradução de $(1938$, p. 7$)$ do referido texto diz que "Empregando como tijolos esses e outros conceitos semelhantes, Freud construiu um modelo altamente complexo e extraordinariamente engenhoso da mente como uma máquina neurológica".

Garcia-Rosa (2009, p. 47) refere que "O Projeto não é, portanto, uma tentativa de explicação do funcionamento do aparelho psíquico em bases anatômicas, mas, ao contrário, implica uma renúncia à anatomia e a formulação de uma metapsicologia". Dessa forma a teoria psicanalítica de Freud se distancia do modelo anatômico e cria novos conceitos para um modelo metapsicologico.

Freud (1923) no prosseguimento de seus estudos escreve sobre as instâncias desse aparelho psíquico, denominando-o de $1^{a}$ Tópica, esse modelo topográfico é considerado um dos principais elementos da metapsicologia freudiana. Ele introduziu a ideia de que o aparelho psíquico é composto por áreas diferentes da mente, regidos por diferentes processos.

Nessa $1^{a}$ tópica descrita por Freud ele concebe três regiões do aparelho psíquico sendo eles, consciente (Cs) que seria o local que possui acesso à consciência, o pré-consciente $(\mathrm{P}-\mathrm{cs})$ a outra região que corresponde a localização dos conteúdos que podem vir a consciência de maneira mais simples, e $\circ$ inconsciente (Ics) onde estão localizados os conteúdos reprimidos se tornando inacessível a consciência.

Assim, Freud (1923) relaciona esses conceitos referentes à primeira tópica dizendo que os preconizou a partir da teoria da repressão do texto de 1915, explicando que o reprimido é o próprio modelo do que é o inconsciente. $E$ que há dois tipos de inconsciente: o latente, porém capaz de consciência e o reprimido não possível de consciência:

Esta nossa visão da dinâmica psíquica não pode deixar de influir na terminologia e na descrição. Ao que é latente, tão só descritivamente inconsciente, e não no sentido dinâmico, chamamos de pré-consciente; o termo inconsciente limitamos ao reprimido dinamicamente inconsciente, de modo que possuímos agora três termos, consciente (cs), pré-consciente (pcs) e inconsciente (ics), cujo sentido não é mais puramente descritivo (FREUD, 1923, p. 16).
Dessa forma, Freud (1923, p. 15) preconiza a ideia de uma formação, uma organização coesa onde os processos psíquicos de uma pessoa, denominados de "EGO da pessoa", se liga a consciência, esses acessos possibilitam a descarga dessas excitações no mundo externo, assim é essa instância psíquica que exerce $o$ controle sobre todos os seus processos parciais, além disso, do ego partem as repressões por meio das quais algumas tendências psíquicas precisam ser excluídas da consciência.

Na sequência de seus estudos Freud percebeu que esse primeiro modelo topográfico não era suficiente para explicar os processos mentais do aparelho psíquico, assim no texto $O$ Ego e o ld (1923) propõe um novo modelo constituído de Id, Ego e Superego, denominando-o de $2^{a}$ tópica do aparelho psíquico.

Freud (1923) explica que este modelo é composto por três partes que estão interligadas e trabalham nas ações e reações do indivíduo, sendo eles: ० Id, Ego e Superego. O Id, é a forma irracional da mente que permite ao indivíduo agir de forma impulsiva, ou seja, é a forma de ação e reação onde o sujeito se expressa sem ao menos pensar, o ld na $2^{a}$ tópica é denominado inconsciente, é o depósito das energias psíquicas (FREUD, 1923).

O ego é aquela parte do id que foi modificada pela influência do mundo externo, e procura substituir o princípio de prazer que reina sem restrições no id pelo princípio de realidade. No ego a percepção exerce um papel que no id é o instinto, assim - ego representa a razão. $O$ ego tem origem no inconsciente, sua função seria agir como mediador, integrador, harmonizador, entre as pulsões do id, e as exigências e advertências do superego e as demandas da realidade externa (FREUD, 1923).

É fácil ver que o Ego é a parte do ld modificada pela influência direta do mundo externo, sob mediação do $\mathrm{Pcp}-\mathrm{Cs}$, como que um prosseguimento da diferenciação da superfície. Ele também se esforça em fazer valer a influência do mundo externo sobre o $l d$ e os seus propósitos, empenha-se em colocar o princípio da realidade no lugar do princípio do prazer, que vigora irrestritamente no Id. A percepção tem, para o Eu, o papel que no Id cabe ao instinto. O Eu representa o que se pode chamar de razão e circunspecção, em oposição ao ld, que contém as paixões (FREUD, 1923, p.23). 
A última instância proposta por Freud é o Superego que se caracteriza pela instância que consiste na interdição do que lhe é proibido. $O$ superego representa a lei, ele inicia-se na dissolução do complexo de Édipo no qual a criança precisa deixar o seu primeiro objeto de amor, entendendo que não the pertence. È o lugar de censura, do corte, envolve o pensamento do certo e errado, se torna responsável pelo desenvolvimento da consciência moral. $O$ Superego não é puramente um resquício das escolhas objetais iniciais do Id; possui também o sentido de uma ativa formação reativa a este. "Sua relação com o Eu não se esgota na advertência: "Assim (como o pai) você deve ser"; ela compreende também a proibição: "Assim (como o pai) você não pode ser, isto é, não pode fazer tudo o que ele faz; há coisas que continuam reservadas a ele" (FREUD, 1923, p.32).

Como os pais, em especial o pai, foram percebidos como obstáculo à realização dos desejos edípicos, o Eu infantil fortificou-se para essa obra de repressão, estabelecendo o mesmo obstáculo dentro de si. Em certa medida tomou emprestada ao pai a força para isso, e esse empréstimo é um ato pleno de consequências. O Super-eu conservará o caráter do pai, e quanto mais forte foi o complexo de Édipo tanto mais rapidamente (sob influência de autoridade, ensino religioso, escola, leituras) ocorreu sua repressão, tanto mais severamente o Supereu terá domínio sobre o

Eu como consciência moral, talvez como inconsciente sentimento de culpa (FREUD, 1923, p. 32)

Dessa maneira, Freud descreveu o aparelho psíquico como um conceito preponderante para a compreensão dos processos mnemônicos do sujeito.

Nessa perspectiva, a teoria freudiana preconiza que desde $\circ$ nascimento, os indivíduos são dotados de uma base biologicamente instintual, Freud (1915), no princípio de sua teoria na obra "Os instintos e seus destinos" e/ou outra versão descrita como "As pulsões e suas vicissitudes" (1915, p. 41), define pulsão como uma energia psíquica que se acumula no interior de um indivíduo gerando uma tensão que necessita ser descarregada ou satisfeita.

No texto "Três ensaios sobre a teoria da sexualidade" de 1905, Freud cita pela primeira vez o termo Pulsão, relacionando-o à sexualidade humana. As pulsões são fatores motivadores da dinâmica da constituição do sujeito na vida mental, ou seja, os processos mentais não ocorrem por acaso. Há uma causa para cada memória revivida, cada pensamento, sentimento ou ação de forças biológicas que liberam energia mental, acreditando no desenvolvimento do sujeito, passando por uma série de estágios durante a infância em busca do prazer focadas em determinadas áreas erógenas como uma força motriz por trás do comportamento, uma energia psicossexual ou libido, classificando-os em dois grandes grupos: instintos de vida (Eros) e instintos de morte (Thanatos), contudo, Freud só formalizou tal hipótese em 1920 no texto "Além do principio do prazer", (FREUD, 1915/1920).

Freud (1915) propõe que um indivíduo vivenciando frustração em qualquer estágio de desenvolvimento psicossexual, experimentaria ansiedades que persistiriam na vida adulta como um transtorno mental funcional, caracterizando uma neurose (FREUD, 1915). Esse conceito de pulsão enunciado por Freud traz a ideia de dois tipos de estímulos: externos e internos. Quando ocorre um estimulo externo, o sujeito faz uso de mecanismos de fuga para se livrar do estimulo. Porém, quando são internos não há possibilidade de fuga, e o alívio deve ser alcançado de outra maneira:

Os estímulos externos colocam apenas a tarefa de subtrair-se a eles, o que acontece então por movimentos musculares, dos quais um alcança o fim e, sendo o mais apropriado, torna-se disposição hereditária.

Os estímulos instintuais que surgem no interior do organismo não podem ser liquidados por esse mecanismo. Portanto, colocam exigências bem mais elevadas ao aparelho nervoso, induzem-no a atividades complexas, interdependentes, as quais modificam tão amplamente o mundo exterior, que ele oferece satisfação à fonte interna de estímulo, e sobretudo obrigam o aparelho nervoso a renunciar à sua intenção ideal de manter a distância os estímulos, pois sustentam

um inevitável, incessante afluxo de estímulos (FREUD, 1915$, p. $41 / 42)$.

Assim, na teoria psicanalítica do ponto de vista econômico o aparelho psíquico é regido pelo principio do prazer, no curso dos processos psíquicos. Acreditase que ele é sempre instigado por tensões de desprazer e toma uma direção para que seu resultado seja a diminuição dessa tensão, ou a sua evitação, ou a geração do prazer (FREUD, 1920, p. 121). 
$E$ ao descobrir que mesmo a atividade dos mais evolvídos aparelhos psíquicos está sujeita ao princípio do prazer, ou seja, é automaticamente regulada por sensações da série prazer-desprazer, dificilmente podemos rejeitar o pressuposto seguinte, de que tais sensações reproduzem a maneira como se realiza a sujeição dos estímulos. Seguramente no sentido de que a sensação de desprazer está ligada ao aumento, e a sensação de prazer ao decréscimo do estímulo. Seguramente no sentido de que a sensação de desprazer está ligada ao aumento, e a sensação de prazer ao decréscimo do estímulo (FREUD, 1915, p. 42).

Dessa forma, Freud (1915, p.41) reinsere os elementos da pulsão descritos nos três ensaios (1905): - Impulso, que seria o elemento motor, relacionado à força que o representa; $A$ meta de um instinto é sempre a obtenção do prazer; $O$ objeto do instinto é aquele com $\circ$ qual $\circ$ instinto pode obter a sua meta; A fonte do instinto abarca o processo somático num órgão ou parte do corpo, de que o estímulo é representado na psique pelo estímulo.

Freud (1905) dando continuidade aos seus estudos sobre a constituição do aparelho psíquico menciona outro conceito importante de sua teoria, sendo este diretamente ligado ao desenvolvimento psicossexual da criança, escrito pela primeira vez em 1905, no texto "Os três ensaios sobre a Teoria da sexualidade". Refere-se à proposta das fases do desenvolvimento psicossexual o qual foi posteriormente aprimorado, em 1913, (FREUD, 1905).

Ao escrever sobre as fases do desenvolvimento psicossexual, Freud (1905, p. 107). Caracterizou-as como: "organizações pré-genitais" e postulou seus conceitos sobre elas denominando de "fases de desenvolvimento da organização sexual". Nessa época ele considerou duas fases em especial chamando-as de oral e sádico anal. A fase oral representada pela atividade sexual ainda não afastada da deglutição de alimentos, cujo objetivo sexual está ligado à incorporação do objeto. Um resíduo dessa fase seria $\circ$ ato de chupar $\circ$ dedo, nesse aspecto trocou-se a atividade sexual da alimentação. Na fase sádico anal, a zona erógena é especialmente a mucosa intestinal, cuja atividade é causada pelo instinto de apoderamento por meio da musculatura do corpo, como órgão e meta sexual passiva (FREUD, 1905 , p. 108).
Em (1923, p. 155) escreve sobre a fase posterior "a organização genital infantil - um acréscimo à teoria da sexualidade", no qual ele irá relatar que:

No estágio da organização genital infantil que então se segue há masculino, mas não feminino; a oposição

é: genital masculino ou castrado. Apenas ao se completar o desenvolvimento, na época da puberdade, a polaridade sexual coincide com masculino e feminino.

O masculino reúne o sujeito, a atividade e a posse do pênis, o feminino assume o objeto e a passividade. $A$ vagina é então estimada como abrigo do pênis, tornase herdeira do ventre materno (FREUD, 1923, p.155)

Freud no texto sobre os ensaios explica que essas pulsões parciais estão ligadas a zonas erógenas, referindo à sexualidade infantil, porém, na puberdade, não significa que são abandonadas, elas funcionam na infância no molde dos prazeres, embora na puberdade a sexualidade encontre certa organização (que é esperada) essas pulsões parciais ainda se acham ativas, mesmo tendo a precedência dos genitais ou sob o destino do recalque (FREUD, 1905).

Chemama, (1995) cita que cada fase de desenvolvimento corresponde à forma de organização da libido, no qual considera a energia psíquica em torno de uma zona erógena, correspondendo a uma relação de objeto, o que convoca uma tendência natural para o desenvolvimento contínuo das fases. Essa energia psíquica inerente ao sujeito, a qual Chemama (1995, p.126) define como: "Libido é a energia psíquica das pulsões sexuais, que encontram seu regime em termos de desejo, de aspirações amorosas, e que, para Freud, explica a presença e manifestação do sexual na vida psíquica". Caracteriza-se por ser uma fonte original de energia afetiva que mobiliza o organismo na obtenção de seus objetivos, sofre progressivas organizações durante o desenvolvimento, em torno de zonas erógenas corporais. Essa energia pulsional é voltada para a obtenção de prazer (Chemama, 1995).

D'Andrea, (1980), traz uma contribuição relatando que as fases do desenvolvimento ocorrem em sete períodos: oral, anal, fálica, latência, adolescência, maturidade e velhice, em cada fase o sujeito deve aprender a resolver as dificuldades pertinentes a elas, ocasionadas do próprio crescimento físico e da interação com o meio. As normas sociais ou a cultura 
na qual o sujeito está inserido interfere na maneira como se solucionam os diversos problemas determinantes na passagem de uma fase para a outra e na constituição do tipo característico da subjetividade do sujeito (D'ANDREA, 1980).

A psicanálise postula outro conceito fundamental na constituição do sujeito que é o complexo de Édipo, e que está diretamente ligada às fases do desenvolvimento. Freud (1920) descreve ser o Complexo de Édipo determinante na estruturação da constituição psíquica do sujeito, e diz que a "A psicanálise conhece a identificação como a mais antiga manifestação de uma ligação afetiva a outra pessoa. Ela desempenha um determinado papel na pré-história do Complexo de Édipo" (FREUD, 1920, p.46).

Para a compreensão do conceito sobre o Complexo de Édipo, cita-se Laplanche e Pontalis:

Conjunto organizado de desejos amorosos e hostis que a criança sente em relação aos pais. Sob a sua forma dita positiva, o complexo apresenta-se como na história de Édipo-Rei: desejo da morte do rival que é a personagem do mesmo sexo e desejo sexual pela personagem do sexo oposto. Sob a sua forma negativa, apresenta-se de modo inverso: amor pelo progenitor do mesmo sexo e ódio ciumento ao progenitor do sexo oposto. Na realidade, essas duas formas encontram-se em graus diversos na chamada

forma completa do complexo de Édipo. Segundo

Freud, o apogeu do complexo de Édipo é vivido entre os três e os cinco anos, durante a fase fálica; o seu declínio marca a entrada no período de latência. É revivido na puberdade e é superado com maior ou menor êxito num tipo especial de escolha de objeto.

O complexo de Édipo desempenha papel fundamental na estruturação da personalidade e na orientação do desejo humano. Para os psicanalistas, ele é o principal eixo de referência da psicopatologia; para cada tipo eles procuram determinar as formas particulares da sua posição e da sua solução (LAPLANCHE E PONTALIS, 2016 p. 77)

Nasio (2017) menciona que o Édipo é como um entrave, sendo um desejo sexual maduro vivenciado na cabeça e no corpo infantil de uma criança, tendo como objeto os pais.

A criança edipiana é uma criança alegre que, em toda inocência, sexualiza os pais, introduzindo-os em suas fantasias como objetos de desejo e imitando sem pudor nem senso moral seus gestos sexuais

de adultos. É a primeira vez na vida que a criança conhece um movimento erótico de todo seu corpo em direção ao corpo do outro. Não se trata mais de uma boca tendendo para um seio, mas de um ser integral que quer apertar o corpo inteiro da mãe. Ora, se é verdade que a criança edipiana fica feliz ao desejar e obter prazer com isso, é mais verdade ainda que desejo e prazer a assustam, pois ela os teme como um perigo

(NASIO, 2007, p 10).

O autor diz que no menino o órgão peniano é a parte do corpo mais repleta de sensações que the confere como a zona erógena predominante, já que esse prazer sentido pela criança faz referência a todos os outros prazeres corporais. Por volta da idade de 4 anos todo prazer corporal independente do local do corpo em excitação, é reportado ao seu órgão (pênis) sob diversas formas de sensações. Também se torna muitas vezes motivo de exibição em público. Assim, diz que todos esses prazeres sentidos ora pelo olhar, pela boca, pela exibição refletem no nível de seu pequeno órgão, efetivando a vivência da excitação genital. $O$ autor refere que o pênis para o menino se torna:

Apêndice visível, facilmente manipulável, erógeno e eréctil, o pênis atrai a mão, assim como a teta atrai

os lábios e a língua; o pênis convoca os olhares, atiça a curiosidade dos meninos e das meninas e lhes inspira fábulas, ficções e bizarras teorias infantis. $A$

pregnância imaginária do pênis é tamanha que o menino faz dele seu objeto narcísico mais precioso, a coisa pela qual tem mais apego e orgulho de possuir. Assim, tal culto do pênis eleva o pequeno órgão ao nível de símbolo do poder absoluto e da força viril

(NASIO, 2007, p. 23).

Com relação ao que ocorre no gênero feminino em relação à passagem pelo Complexo de Édipo e castração, Freud (1933, p.133) menciona: "A identificação de uma mulher com sua mãe permite-nos distinguir duas camadas: a pré-edipiana, sobre a qual se apoia a vinculação afetuosa com a mãe e esta é tomada como modelo, e a camada subsequente, advinda do complexo de Édipo, que procura eliminar a mãe e tomar-lhe o lugar junto ao pai".

Freud (1931) em seus estudos sobre a sexualidade feminina afirma que existem diversos entraves 
e dúvidas a respeito do complexo de Édipo, causados pela diferença anatômica entre os sexos. $\mathrm{Na}$ menina a principal característica é que ela precisa se desligar do objeto feminino representado pela mãe. A menina descobre a existência do pênis no menino, se dá conta que não possui o órgão e diante da decepção, culpa a mãe, acreditando que ela permitiu que nascesse sem $\circ$ pênis, nesse momento surge sentimentos de inferioridade, vergonha, ciúme, inveja do pênis e raiva depositada na mãe, e na sua raiva acaba se voltando para $\circ$ pai, nomeando-o como seu objeto de amor, acreditando que tomará - lugar da mãe.

De acordo com Freud (1924) o complexo de Édipo na menina vai além de assumir o papel da mãe junto ao pai, renunciar o pênis é algo que não é aceito naturalmente, e ela buscará algum tipo de compensação.

O complexo de Édipo, portanto acontece quando a criança está atravessando a fase fálica (organização genital), quando despertam sentimentos de amor e ódio direcionados para aqueles que lhes são mais próximos, os pais. Geralmente nessa fase, a criança, devido ao desenvolvimento de sua autonomia se depara com várias proibições que antes the eram desconhecidas. É nesse momento, que percebe que a família e a sociedade começam a impor regras, limites e padrões a serem seguidos Entretanto, é importante dizer que cada criança passa por essa fase de maneira peculiar, levando em conta as fases anteriores (LAPLANCHE E PONTALIS, 2016).

Assim, os recortes teóricos vistos até o momento possibilitam a compreensão dessa dinâmica do aparelho psíquico, relacionadas à constituição do sujeito, apontando para outros aportes teóricos que dialoga com o que se propõe o presente trabalho.

\section{A função materna na constituição do sujeito}

Após contemplar recortes de alguns conceitos da psicanálise, vamos pensar a respeito da constituição do sujeito, e como as fases de desenvolvimento citadas anteriormente vão se ligando formando uma cadeia de significantes. E para essa compreensão segue-se nesse estudo, a reflexão sobre a função materna e como ela desempenha papel fundamental para a constituição do sujeito. Para essa expla- nação parte-se do pensamento de dois autores, Julieta Jerusalinsky e Donald Woods Winnicott.

Dois importantes expoentes da psicanálise, sendo um clássico e o outro mais contemporâneo.

Donald W. Winnicott ao longo de sua trajetória trouxe muitas contribuições a respeito da psicoterapia com crianças, pediatra por formação, sendo influenciado principalmente pelos pressupostos teóricos de Melanie Klein, no qual fundou sua própria teoria a partir de suas experiências com crianças. Sua proposição tem sido disseminada ao longo dos anos e se tornado ferramenta de grande valia na clínica infantil.

De igual forma, Julieta Jerusalinsky numa visão mais contemporânea, apoiada pela teoria de JacquesMarie Émile Lacan, outro importante psicanalista, tem contribuído com sua experiência na clínica infantil, especialmente no trabalho com transtornos mentais graves, seus escritos e cursos tem sido instrumento de ampla ajuda aos psicólogos e educadores no trabalho com crianças.

Mesmo sendo influenciados por diversas visões teóricas da psicanálise os referidos autores descrevem pontos importantes que podem ser convergidos no que tange à constituição do sujeito, destacando a importância da função materna que ambos evidenciam em seus relatos, pressupostos diferentes, mas que possuem a mesma finalidade: a saber, 0 desenvolvimento saudável do ego.

Nos pressupostos teóricos de Jeruzalinsky, ao falar de constituição subjetiva em Psicanálise, torna-se necessário explicitar que um bebê já nasce com uma história lhe esperando. A fantasmática parental já preparou desde muito antes de seu nascimento um lugar para que essa criança venha ocupar. $E$ isso depende de toda história dos pais. Como aponta Jerusalinsky (2014) de uma estrutura simbólica que antecede o nascimento, mas que não é suficiente para determiná-la, pois é necessário que, para um bebê vir a ser um sujeito, um Outro exerça a função materna, função que não se pode considerar natural, como é do ponto de vista do senso comum. A ideia de função materna na Psicanálise é aquela que por meio dos cuidados envolvidos pelo desejo instaura nesse corpo uma subjetividade, ou seja: 
"Por meio desse fino trabalho de bordado da mãe entre o corpo e linguagem, ao exercer seus cuidados, instaura-se sorrateiramente no bebê um gozo que, onde se pretende o auto erótico, já leva a marca do Outro" (Jerusalinsky 2014, p. 25).

A princípio, um bebê não sabe $\circ$ que the acomete o corpo, não sabe quando tem fome, quando tem frio, se essa pequena criança é deixada, não há um saber de como sobreviver. Há uma prematuridade para isso, portanto, cabe a quem desempenhará essa função de maternagem fazer contornos que dizem a essa criança quem ela é, o que quer o que pode e não pode. Jerusalinsky (2014) diz que ocupar-se dessa função, deve favorecer um gozo pela passividade da criança em relação a essa mãe, ou seja, que essa total dependência do bebê, precisa gerar um prazer, ainda que custem muitos esforços. Pois isso favorece que a mãe se ocupe do que se passa com seu bebê, numa identificação e possa the devolver, em forma de significantes:

Vemos, portanto, como é necessário que o que se passa no organismo do bebê se constitua como gozo da mãe, para que esta possa transmitir-lhe o saber por meio do qual o bebê fará sua a representação daquilo que o acomete, fará do padecido nesse organismo real, a experiência representada em um corpo imaginário e simbólico (Jerusalinsky, 2014 ) p.28).

Para que isso ocorra, não existe uma forma pronta de como é ser mãe, cada família irá por si mesma, diante de todas suas experiências, encontrar meios de exercer suas funções. Porém, existem condições para que esse bebê possa constituir-se como sujeito e isso se dá por esse laço precoce com seu cuidador. Por exemplo, no começo de sua vida, um bebê comporta-se com agitações motoras reflexas que são tomadas por um adulto que se ocupa dessa função materna como uma resposta, que por meio do seu saber inconsciente diz a criança "olha! Você está feliz em ver a mamãe". Sabe-se que este pequeno ser ainda não é capaz de fazer essa associação, mas essa mãe é capaz de já supor algum desejo, sentimento nesse filho, porque aposta/sugere que ali há um sujeito em desenvolvimento. Em outro momento, o bebê começa a emitir sons vocais, mais uma vez essa mãe lhe supõe uma conversa, ora fala por ele, ora fala com ele, mas ainda lhe dá um espaço para responder, convocando para um diálogo. Diante disso, a mãe sustenta um lugar para essa criança, um lugar de sujeito:
Nessa direção, podemos dizer que é a mãe que dá a voz ao bebê ao tomar suas fonações como um chamado. Se a mãe toma o grito do bebê apenas como um som, apenas discrimina em que nota da escala musical o som foi emitido, em lugar de perguntar "que foi, nenê?", ou seja, de produzir uma interrogação pelo enigma do desejo que supõe ao bebê, teremos ali apenas a dimensão da phone, mas não dá vox

(Jerusalinsky, 201 4, p. 69)

Ainda sobre isso, Jerusalinsky $(2014$, p. 75$)$ diz que por meio dessas trocas, o bebê passa a ser "pulsionalizado, erotizado e, simultaneamente tomado no funcionamento da linguagem", isso o inscreve no circuito pulsional. Para os psicanalistas, há quatro eixos que se tornam imprescindíveis voltar à atenção na clínica de bebês, já que a intervenção é na relação da criança com seus pais.

As operações que serão observadas são: Suposição de sujeito, estabelecimento de demanda, alternância presença e ausência, e alterização. Esses eixos são condições para que haja instauração de um sujeito do próprio desejo e dependem de que um Outro - faça. Por exemplo, na suposição de um sujeito, a mãe toma as produções do bebê, ainda que sejam automáticas, como sendo produzidas por um desejo. Ao estabelecer uma demanda, a função materna começa a diferenciar essas produções, Jerusalinsky (2012) aponta que é comparável a uma interpretação e tradução do que ocorre com o bebê, ou seja, por meio do choro, da vocalização, do tônus, a mãe compreende o que se passa com seu filho e pode então dizer a ele. Enquanto isso, a pessoa encarnada na função materna, introduz uma alternância entre a presença e ausência, isso quer dizer que através dessas demandas do bebê, ela não responda unicamente com presença ou ausência, mas que possa alternar em boa medida. Convém frisar que não se trata apenas de uma questão física, já que:

A presença e a ausência são tomadas aqui numa dimensão psíquica que não física. Uma mãe pode estar fisicamente presente, prestar mecanicamente os cuidados básicos ao seu bebê e, entretanto, não estar ali com seu desejo, seu investimento, sua atenção voltados para o bebê, por exemplo. Ou, ao contrário, a mãe pode ausentar-se fisicamente e toma tantas precauções para que nenhuma diferença compareça que o bebê pode não registrar sua saída (Jerusalinsky, 2012 p. 251). 
O último eixo é a alterização, que consiste em inserir o bebê numa ordem de restrição, interdição e lei social. Julieta Jerusalinsky descreve em seu livro (2012), "Enquanto o futuro não vem", seguindo uma linha da constituição subjetiva, no qual a criança vive um momento de confusão entre seu corpo e o corpo materno, onde está alienada a um desejo que é do Outro, para que depois um terceiro, possa fazer uma intervenção que chamamos de função paterna. Claro que, a função paterna já vem sendo exercida, ora como um terceiro já se introduzindo nessa relação, ora como a própria inscrição da função paterna na mãe, que a possibilita alternar a ausência e a presença, que funda o superego (JERUSALINSKY, 2012).

Donnald Woods Winnicott (2005), escreve sobre como acontece esse desenvolvimento e especialmente a relação mãe e bebê. Ele relata que no desenvolvimento emocional da criança há uma disposição inata que corresponde ao crescimento do corpo e ao desenvolvimento de algumas funções. Exemplificando, assim como comumente o bebê senta por volta dos cinco meses, dá seus primeiros passos por volta dos 12 meses, igualmente, há um processo evolutivo emocional, contudo, tal desenvolvimento não pode ser constatado na presença e/ ou ausência de condições satisfatórias, e é esse aspecto que torna difícil estabelecer quais condições são favoráveis e/ou não favoráveis para esse desenvolvimento.

No principio há a dependência absoluta em relação aos aspectos ambientais e emocionais, porém no percurso do desenvolvimento, a depender de como se dá a relação da criança com a mãe, alguns percalços podem contribuir para afetar a constituição psíquica, conforme nos diz Winnicott (2005):

Muita coisa acontece no primeiro ano de vida da criança: o desenvolvimento emocional tem lugar desde o princípio; num estudo da evolução da personalidade e do caráter é impossível ignorar as ocorrências dos primeiros dias e horas de vida (e mesmo do último estágio da vida pré-natal, no caso de crianças pósmaturas); e até a experiência do nascimento pode ser significativa. $O$ mundo não parou de girar a despeito de nossa ignorância no que toca a estes assuntos, pois há algo na mãe de um bebê que a torna

particularmente qualificada para proteger seu filho nesta fase de vulnerabilidade, e que a torna capaz de contribuir positivamente com as claras necessidades da criança. A mãe é capaz de desempenhar esse papel de sentir segura; de se sentir amada em sua relação com - pai da criança e com a própria família; e ao sentir-se aceita nos círculos cada vez mais amplos que circundam a família e constituem a sociedade (WINNICOTT, p. 3, 2005).

Para Winnicott a mãe tem papel fundamental no desenvolvimento da criança, é ela que provê as necessidades de seu bebê, este cuidado e atenção se denominam "holding" caracterizando a função materna. As consequências desse cuidado serão determinantes para a constituição da personalidade da criança, a qual será evidenciada nas futuras relações do individuo com o seu círculo social. A criança se desenvolve a partir do olhar da mãe, o qual funciona como espelho para a criança, propiciando a ela condições necessárias para seu desenvolvimento (WINNICOTT, 1975).

O prazer com que a mãe realiza suas tarefas logo dá a perceber ao bebê que existe um ser humano por trás de tudo o que é feito. Mas o que finalmente leva o bebê a sentir uma pessoa na mãe é, talvez, a capacidade especial da mãe para colocar-se no lugar da criança e, assim entender o que ela sente. Não há regras nem livros que possam suprir essa intuição que a mãe tem das necessidades do bebê, a qual lhe permite realizar, algumas vezes, uma adaptação quase exata a essas necessidades (WINNICOTT, 1964, p.49).

Quanto ao pai, o autor diz que nesse primeiro momento a função paterna está ligada a prover subsídio para a mãe a fim de que ela possa realizar sua função materna de forma que seja satisfatória para este vínculo mãe e bebê, só depois é que o pai entra na relação completando essa tríade familiar, desde que a mãe insira o pai nessa relação. $O$ papel do pai na visão winnicottiana é aquele que dá o suporte para a mãe executar sua função junto a seu bebê. Então, a primeira apresentação da função paterna é garantir que a mãe vivencie esta etapa inicial de maneira tranquila, com segurança.

Nesse ponto o pai pode ajudar. Pode ajudar a criar um espaço em que a mãe circule à vontade. Adequadamente protegida pelo seu homem, à mãe é poupado o trabalho de ter de ocupar-se das coisas externas que acontecem à sua volta, numa época em que ela tanto precisa concentrar-se, quando tanto 
anseia por preocupar-se com o interior do círculo formado pelos seus próprios braços e no centro do qual está o bebê. (Winnicott, 1957, p. 27)

Nesse sentido, o relacionamento inicial do bebê com seus cuidadores é crucial para o seu desenvolvimento e constituição subjetiva. Nessa relação é preciso diferenciar o que pertence à mãe daquilo que pertence ao bebê, havendo dois tipos diferentes de identificação: "a identificação da mãe com seu filho e o estado de identificação do filho com a mãe" (WINNICOTT, p. 15, 2005).

Portanto, é a mãe que insere no contexto uma capacidade amadurecida, pois é a partir dela que a criança vai adquirindo sua percepção de realidade. A identificação da mãe com o bebê, geralmente começa na gestação e ao longo desse processo tende a ser cada vez mais intensa, por esse ângulo, contata-se a identificação da mãe cada vez maior com seu bebê, nesse aspecto a criança é associada pela mãe a de um objeto interno. "O bebê tem outros significados na fantasia inconsciente da mãe, mas é possível que o traço predominante nesta, seja uma vontade e uma capacidade de desviar o interesse do seu próprio self para o bebê" (WINNICOTT, p. 15, 2005).

A mãe suficientemente boa, como afirmei, começa com uma adaptação quase completa às necessidades de seu bebê, e, à medida que o tempo passa, adapta-se cada vez menos completamente, de modo gradativo, segundo a crescente capacidade do bebê em lidar com o fracasso dela (Winnicott 1975, p.24).

Diante desses recortes teóricos sobre a constituição psíquica do individuo constata-se que as relações parentais têm papel fundamental na constituição do sujeito. $E$ as dificuldades encontradas por mães e bebês são analisadas durante o processo terapêutico (LAPLANCHE E PONTALIS, 1998).

Se durante esse processo de subjetivação ocorre algum impasse ou se há impedimentos no laço entre a criança e o seu cuidador, há o risco de que essas fases não se completem ou até mesmo não se inicie, abrindo a possibilidade para futuras psicopatologias. Cada fase tem papel fundamental para o desenvolvimento, uma vez que sinaliza a construção de um ego saudável. $E$ é neste momento que o papel do psicanalista é de extrema importância, onde será um suporte das funções parentais a partir da transferência estabelecida, possibilitando um lugar onde possa haver esse retorno as fases não satisfeitas no campo do desejo (JERUSALINSKY, 2012).

\section{A relação terapêutica, a Transferência e a Contratransferência}

Tendo como base os recortes teóricos dos autores citados podemos nesse momento tentar relacionar os conceitos abordados que apontam para a importância da relação vincular mãe e bebê para a constituição psíquica. No processo analítico o sujeito reproduz as cenas das fases infantis onde é possível ao analista distinguir onde houveram conflitos. $O$ processo analítico se constitui por meio de dois integrantes: analista e paciente. Além desses, $O$ setting ${ }^{1}$ e o enquadre ${ }^{2}$ também servem como composição importante da cena analítica, pois revelam as características tanto do terapeuta quanto do paciente. Por meio da transferência é que esse fenômeno acontece na relação vincular paciente/terapeuta, onde o desejo do paciente se apresenta, como uma reprodução de suas lembranças da infância, cujas imagens parentais e seus substitutos são projetados no analista, e deste modo os sentimentos, desejos, impressões dos primeiros vínculos afetivos são revividas na época presente (FREUD, 1914).

Dentro deste aspecto podem ser citados dois termos psicanalíticos importantes que cooperam para a compreensão do vinculo terapêutico que se estabelece na clínica, e como se relacionam as fases de desenvolvimento. Esses termos são Fixação ${ }^{3}$ e Regressão ${ }^{4}$, descritos por Zimerman (1999), no qual relata que a noção de fixação geralmente

\footnotetext{
1 Setting - Tradução portuguesa do termo psicanalítico setting, em cujo verbete especifica está descrita sua importância na técnica e na prática analítica (Zimmermann, 2001).

2 Enquadre - Comumente traduzido como enquadre, o setting pode ser conceituado como a soma de todos os procedimentos que organizam, normatizam e possibilitam o processo psicanalítico (Zimmermann, 2001)

3 Fixação - O fato de a libido se ligar a pessoas ou imagos, de reproduzir determinado modo de satisfação e permanecer organizada segundo a estrutura característica de uma de suas fases evolutivas. A fixação pode ser manifesta e real ou contribuir uma virtualidade prevalescente que abre ao sujeito o caminho de uma regressão (Laplanche e Pontalis, 2016).

4 Regressão - Retorno a formas anteriores ao desenvolvimento dos pensamentos das relações de objeto e da estruturação do comportamento (Laplanche e Pontalis, 2016).
} 
está ligada a regressão, significando que quando um individuo não conseguiu de maneira satisfatória evoluir nas fases de desenvolvimento passando de uma para outra, significa que ainda não teve sua satisfação libidinal, e caso surja uma angústia muito forte num dado momento da evolução, como resultado do temor de se ligar a um objeto, cria-se um ponto de fixação. Assim, a fixação é um momento que se interrompe o processo evolutivo, devido à impossibilidade de satisfação de um desejo, resultando na constituição de um ego mais frágil. Esta interrupção gera angústia e como consequência, ocorre à regressão com o objetivo de repetir a situação traumática a fim de se elaborar a situação dolorosa (ZIMERMAN, 1999).

Esses conteúdos apontam para outro conceito que Freud denominou transferência, tornando-se um constructo teórico fundamental permitindo a articulação da teoria com a clínica psicanalítica. A transferência se estabelece a partir da realidade psíquica do analisando, por meio da expressão dos seus desejos, sentimentos, e outros aspectos da sua subjetividade. No texto Recordar, Repetir e Elaborar, Freud (1914) explica que a transferência propicia um lugar que faz a mediação entre a patologia e a vida real, por meio do qual o trajeto de uma para a outra é realizada, ou seja, em análise, o sujeito recorda o que esqueceu e foi reprimido, fala sobre estas questões esquecidas acreditando que tinha conhecimento delas, mas não pensava sobre. Também pode acontecer, em certos casos, que ao invés do paciente recordar desses conteúdos reprimidos ele o expresse em forma de atuação com o analista. As atuações nem sempre são recordações, pois isso não é consciente, geralmente o paciente não sabe que está repetindo. O paciente recorda dos conflitos traumáticos, revive com o terapeuta até o momento que esses são elaborados (FREUD, 1914).

Segundo Laplanche e Pontalis (1998, p. 514) "Transferência designa em psicanálise $\circ$ processo pelo qual os desejos do inconsciente se atualizam sobre determinados objetos no quadro de certo tipo de relação estabelecida entre eles $\mathrm{e}$, eminentemente, no quadro da relação analítica". O manejo da transferência é um componente importante da téc- nica de análise, além de ser também um fenômeno universal das relações humanas, pois define o êxito das relações de cada individuo no seu ambiente familiar e social (LAPLANCHE E PONTALIS, 2016).

Outro conceito que também faz ligação a essa dinâmica das relações vinculares no setting terapêutico, é a contratransferência conforme define Laplanche e Pontalis (1998, p. 102), com o "conjunto das reações inconscientes do analista a pessoa do analisando e, mais particularmente a transferência deste".

São poucos os escritos de Freud a esse respeito, porém a primeira menção explicita sobre contransferência foi citada em (1910, p. 130) "no congresso de psicanálise de Nuremberg, no qual alguns autores traduziram do alemão como transferência recíproca". Nessa época Freud usou o termo para fazer referência a resistência inconsciente do terapeuta ao processo analítico. Nesse sentido, Zimerman (1999) referindo Freud (1914) descreve a constratransferência como sendo a influência do analisando sobre os sentimentos inconscientes do analista, mencionando que nenhum analista vai além do que seus próprios complexos e resistências internas toleram, alegando a necessidade da análise pessoal. Ela pode surgir como atitude espontânea do analista e pode ser usada para facilitar o tratamento, mas também pode dificultar se ele não conseguir discriminar o sentimento envolvido nessa interação.

Dessa forma, a relação terapêutica em todas as idades (crianças, adolescentes, adultos) possibilita ao sujeito rememorar elaborar seus traumas, pois, é por meio da interação com o outro que ele se constitui enquanto sujeito, e essa constituição nunca acaba já que está em constante transformação, e como pontuamos anteriormente está diretamente ligada a sua energia psíquica.

Diante disso, é possível testificar que esse vinculo terapêutico reproduz as primeiras relações objetais do sujeito nos seus processos de desenvolvimento no qual não puderam satisfazer o desejo, e dessa forma possibilita compreender a dinâmica intrapsíquica na vida do sujeito, evoluindo para um processo terapêutico significativo (ZIMERMAN, 1999). 


\section{Considerações finais}

O presente estudo possibilitou constatar a importância das teorias apresentadas, no qual foi aludido ao longo da pesquisa, um recorte teórico psicanalítico a respeito da constituição do sujeito, evidenciando, sobretudo a função materna na perspectiva dos autores Donald W. Winnicott e Julieta Jeruzalinsky. E como estes processos relacionados às fases de desenvolvimento (constituição subjetiva), não sendo satisfeitos libidinalmente acarretam conflitos prejudicando o desenvolvimento. A partir das leituras dos autores mencionados foi possível atestar como o conhecimento desses processos promove 0 trabalho na clínica psicanalítica. O terapeuta tendo ciência de como isso ocorre na vida do sujeito, oferece ao seu paciente um lugar onde ele possa ir de encontro ao seu conflito e/ou trauma abrindo caminho para a elaboração.

É no setting terapêutico que o terapeuta se configura como objeto, a fim de que o paciente possa projetar a figura do seu trauma (mãe, pai, ou outra pessoa) e possa reviver com o analista a situação traumática, possibilitando a descarga da energia visando uma saída para o trauma, ou seja, a elaboração do conflito.

Este vínculo do par analítico possibilita ao paciente rememorar seus conflitos, evocar seus desejos e elaborar o conflito existente.

Versando sobre essas relações que o indivíduo vai construindo ao longo de sua vida podemos dizer que $\circ$ vínculo de maior prerrogativa é $\circ$ vínculo mãe e bebê, que começa numa relação de extrema dependência e que vai se tornando independente, dessa maneira podemos dizer que os autores citados para esse trabalho trouxeram fundamental contribuição na compreensão desses processos de desenvolvimento.

$\mathrm{NNa}$ perspectiva de Jerusalisnky compreende-se uma ideia de função materna que é aquela que por meio dos cuidados envolvidos pelo desejo instaura no corpo (bebê) uma subjetividade. A autora nos faz refletir que a história de uma criança não começa no parto, mas bem antes disso. Ela tem inicio nas expectativas e no desejo dos pais de constituir uma família. A pré-história de um bebê inicia com a his- tória dos pais, das memórias de sua própria infância, de sua relação com seus pais, sua experiências boas ou ruins, tudo isso induzindo a um desejo, no qual é transferido para o bebê, que se torna esse gozo dos pais, nesse aspecto o gozo da mãe.

Na visão de Winnicott ele enfatiza como essa relação mãe bebê, tem papel fundamental no desenvolvimento da criança, sendo a mãe a provedora principal de todas as necessidades do bebê inicialmente, segundo o autor a mãe precisa estar disponível para atender todas as demandas desse bebê, a falta desse suporte pode trazer consequências importantes na constituição do sujeito. A criança se desenvolve a partir do olhar da mãe, o qual funciona como espelho para a criança, propiciando a ela condições necessárias para seu desenvolvimento.

Constatamos dessa forma nos relatos de Winnicott como essa relação tem valor estruturante na vida do sujeito, e que a partir dele é que se pode pensar como este se relacionará com seus pares. Igualmente, Julieta Jerusalinsky com uma linguagem distinta de Winnicott, também relata a importância da função materna no processo evolutivo do sujeito, e como essa função tem papel fundamental na inscrição do sujeito no campo da linguagem.

Destacando que a constituição do sujeito está inteiramente ligada às relações parentais, deste modo à atuação do terapeuta na clínica é a escuta dos significantes que constituíram esse bebê no universo de seus pais, possibilitando um lugar de ressignificação de seus conflitos.

Assim, o acolhimento psíquico da figura materna para com seu bebê é de suma importância para a constituição do eu, sendo a base principal para todos demais relacionamentos do bebê no mundo externo. $O$ que leva a pensar que no setting terapêutico a função do analista é se colocar nesse lugar a fim de que o paciente elabore seus conflitos ligados a sua constituição. Evidenciando que cada fase do processo evolutivo é de extrema importância e cabe ao terapeuta na evolução do trabalho psicanalítico perceber, em que momento surgiv o conflito, ou seja, onde o desejo da criança não pode ser satisfeito, e assim proporcionar esse lugar para que o paciente possa reviver e consequentemente promover a elaboração do conflito. O relacionamento saudável 
mãe-bebê representa desse modo, proteção e segurança para a criança, contribuindo essencialmente para o desenvolvimento do psiquismo do sujeito, apontando que na clínica psicanalítica o terapeuta se coloca nessa função.

O analista deve propiciar um ambiente suficientemente bom no qual o paciente possa retomar seu próprio processo de constituição de si mesmo. Cujo objetivo é acompanhar o paciente passo a passo e juntos construir por meio do vinculo terapêutico as fases de sua constituição, da qual a direção do tratamento vai ao sentido de possibilitar ao paciente a ressignificação de seus conflitos.

\section{Contribuições das Autoras}

Saruwatari, AAF participou da concepção, delineamento, busca e análise dos dados da pesquisa, redação do artigo científico e encaminhamento do artigo científico. Gaviglia, VL participou da concepção, delineamento, redação e aprovação final da versão do artigo para submissão. Antonio, CA participou da concepção, delineamento, e aprovação final da versão do artigo para submissão.

\section{Conflitos de interesses}

Nenhum conflito financeiro, legal ou político envolvendo terceiros (governo, empresas e fundações privadas, etc.) foi declarado para nenhum aspecto do trabalho submetido (incluindo mas não limitandose a subvenções e financiamentos, conselho consultivo, desenho de estudo, preparação de manuscrito, análise estatística, etc).

\section{Referências}

Chemama, R. (1995). Dicionário de Psicanálise. Porto Alegre: Artes Médicas.

Freud, S. (1996). Esboço de Psicanálise (Edição Standard Brasileira das Obras Completas de Sigmund Freud, Vol. XXIII). Rio de Janeiro: Imago.

Freud, S. (1923-1925). O Ego e o Id e Outros Trabalhos (Edição Standard Brasileira das Obras Completas de Sigmund Freud, Vol. XIX). Rio de Janeiro: Imago.

Freud, S. (1911-1913). O Caso de Schreber, Artigos sobre a Técnica e Outros Trabalhos (Edição Standard Brasileira das Obras Completas de Sigmund Freud, Vol. XII). Rio de Janeiro: Imago.
Freud, S. (1920-1923). Psicologia das Massas e análise do eu e outros textos (Obras completas volume 15). São Paulo: Companhia das Letras.

Freud, S. (1910-1913). Observações Psicanalíticas sobre um caso de Paranoia (Obras completas volume 10). São Paulo: Companhia das Letras.

Freud, S. (1917-1920). Além do principio do prazer (Obras completas volume 14). São Paulo: Companhia das Letras.

Freud, S. (1914-1916), Os instintos e seus destinos (Obras completas volume 12). São Paulo: Companhia das Letras.

Freud, S. (1923-1925). O Eu e o Id (Obras completas volume 16.). São Paulo: Companhia das Letras.

Freud, S. (1901-1905). Três ensaios sobre a teoria da sexualidade (Obras completas volume 06). São Paulo: Companhia das Letras.

Garcia-Roza, Luiz A. (2009). Freud e o inconsciente (24a ed.). Rio de Janeiro: Jorge Zahar Ed.

Jerusalinsky, J. (2014). A criação da criança: brincar, gozo e fala entre a mãe e o bebê. Salvador, BA: Ágalma.

Jerusalinsky, J. (2012). Enquanto o futuro não vem: $A$ psicanálise na clínica interdisciplinar com bebês. Salvador: Ágalma.

Jerusalinsky, A. (1999). Psicanálise e Desenvolvimento Infantil: um Enfoque Transdisciplinar. Porto Alegre: Artes e Ofícios.

Kupfer, M. C., Bernardino, L. M. F., Jerusalinsky, A., Lerner, R., Pesaro, M. E. (2008). A Pesquisa IRDI: resultados finais. In: Lerner, R. \& Kupfer, M.C. (Orgs.). Psicanálise com crianças: Clínica e pesquisa. São Paulo: Escuta.

Laplanche, J. (1996). Vocabulário de psicanálise. (2a ed.). São Paulo: Martins Fontes.

Laplanche, J. (2016). Vocabulário de psicanálise. (4a ed.). São Paulo: Martins Fontes.

Lescovar, G. Z. (2001). Um estudo sobre as consultas terapêticas e a psicanalise de D. W. Winnicott. Pontifícia Universidade Católica de São Paulo, São Paulo, SP, Brasil. Recuperado de https://sapientia. pucsp.br/handle/handle/15782

Lopes, R. B. (2012). A resistência na obra de Freud [Internet]. Recuperado de https://psicologado.com.br/ abordagens/psicanalise/a-resistencia-na-obra-defreud 
Miranda, A. B. S. (2015). Uma Breve Compreensão sobre o complexo de Édipo [Internet]. Recuperado de https:// psicologado.com/abordagens/psicanalise/umabreve-compreensao-sobre-o-complexo-de-edipo

Nasio, J. D. (2007). Édipo: o complexo do qual nenhuma criança escapa. Rio de Janeiro: Zahar.

Pinto, M. C. (Org.). (2007). O Livro de ouro da Psicanalise. Rio de janeiro: Ediouro.

Carvalho, P. S., Loureiro, M., \& Simões, M. R. (2006). Adaptações psicológicas à gravidez e maternidade. Psicologia e Educação, V(2), 39-49. Recuperado de http://psicologiaeeducacao.ubi.pt/Files/Other/ Arquivo/VOL5/PE\%20VOL5\%20N2/PE\%20 VOL5\%20N2_index_5_.pdf

Roudinesco, E., \& Plon, M. (1998). Dicionário de psicanálise. Rio de Janeiro: Zahar.

Winnicott, D. W. (1975). O brincar e a realidade. Rio de Janeiro: Imago.

Winnicott, D. W. (1985). A criança e seu mundo. Rio de Janeiro: Zahar Editores.

Winnicott, D. W. (2005). A família e o desenvolvimento individual. ( $3 a$ ed.). São Paulo: Martins Fontes.

Zimerman, D. E. (1999). Fundamentos psicanalíticos. Teoria, técnica e clinica. Uma abordagem didática. Porto Alegre: Artmed. 